\section{Cool Jobs}

\section{Expanding the Place of the}

Library Instruction

Curriculum to

Assist Graduates in

Preparing Students

for Atypical Work

Environments

\section{Loriene Roy and Elizabeth Hallmark}

Correspondence concerning this column should be addressed to Kelly Myer Polacek;

email:kmpolacek@gmail.com.

Loriene Roy is a Professor and Graduate Advisor at the iSchool, University of Texas at Austin.

Elizabeth Hallmark is the Internal Communications Leader at Hanger, Inc., in Austin, Texas.
To help our graduates become successful in both traditional and nontraditional information settings, Roy and Hallmark suggest that the requirements listed in modern job descriptions reveal the type of skills and talents we should include in our information science curriculum. This unique perspective allows us to determine how well our information science curriculum matches the skillsets required for atypical "cool jobs" not frequently associated with the library and information science field. They offer suggestions on how to include activities and challenges in a variety of courses to make the instructional setting more closely align with future employment settings. Loriene Roy has taught library instruction and information literacy for more than twenty years, and served as ALA president from 2007 to 2008. Elizabeth Hallmark graduated from the iSchool at The University of Texas at Austin. Hallmark herself has "cool job" experience as the Creative Director for the Texas Comptroller of Public Accounts and more recently as Internal Communications Leader in the public medical sector. Together, these authors summarize findings and offer recommendations for preparing students to become successful in those unusual, atypical work settings-those "cool jobs."-Editor

\section{JOB TITLES AND WORK SETTINGS: TRADITIONAL AND NEW}

New library and information science graduates interested in providing library instruction services might take positions with the familiar job titles of "Public Services Librarian" or "Reference and Instruction Librarian." More recently, however, other job titles have emerged for the instruction librarian (table 1). New graduates find employment in the familiar work settings of public and academic libraries, professional library associations, and academic departments-including LIS schools. Even within these settings, instruction is prominent, as information professionals are called upon to assist job seekers in activities as diverse as filling out online job applications at public access computing stations, helping faculty members and their teaching assistants digitize audio files, and teaching people how to use 3D printers. 


\section{PREPARATION FOR THE MORE TRADITIONAL WORK SETTING}

The traditional course of study preparing LIS graduate students to provide library instruction concentrates the students' studies on sources and services and includes the equivalent of the basic reference course, specialized reference courses, technology electives, and a course on library instruction/information literacy. Working with their faculty advisor, students select coursework in preparation for demonstrating attention to patrons, collections, and technology. In addition, students can gain experience through paid or volunteer positions in libraries where they may design instruction products such as LibGuides, create instruction courses, and integrate instruction into personal and virtual reference services. Students can shadow other instruction specialists, or they can design a Capstone (a culminating graduation project) that focuses on instruction.

We generally advise students interested in public librarianship that they seek experience in a public library and document how well they work with the public. In addition, we advise them to acquire a specialized skill set to offer potential employers, such as youth services programming or web design. For students interested in academic positions, we suggest enrolling in one of our dual-master's degrees; students can earn their MSIS concurrent with Master of Art degrees in Latin American Studies, Women's and Gender Studies, Middle Eastern Studies, Master of Global Policy Studies, Master of Public Affairs, or the Juris Doctor. We also encourage students to write a thesis as their final degree requirement instead of completing a Capstone; the thesis better demonstrates their ability to conduct research and prepare publishable-quality work. For prospective school librarians who may enter LIS programs with an education degree and classroom teaching experience, advisors must additionally include guidance for fulfilling requirements specific for each state school librarian certification.

Despite diverse student goals and requirements, our iSchool (in conjunction with the assistance of field supervisors) prepares students for the many traditional work settings described above. Still, upon landing professional positions that require a portion of their time be spent providing instruction, LIS graduates have not always felt confident in their roles as educators. Recent evidence indicates that librarians engaged in instruction within their work feel that their LIS programs have not sufficiently prepared them for this task. ${ }^{1}$

Professional organizations such as the Association of College and Research Libraries (ACRL) and academic centers like Dartmouth's Center for the Advancement of Learning, have acknowledged this gap in preparation and confidence by providing continuing education that helps information professionals improve their teaching skills. ${ }^{2}$ Successful programs such as Immersion and the Librarians Active Learning Institute (LALI) are taught and organized by experienced practitioners committed to their role as
Table 1. Modern Library Instruction Job Titles

Embedded Librarian

Academic Liaison Librarian

Outreach and Instruction Librarian

Continuing Education Specialist

Student Enrichment Librarian

Information Literacy Coordinator

Customer Service Librarian

Director of Research and Instructional Support

Librarian for Instructional Design, Outreach, and Training

educators. ${ }^{3}$ However, these programs do not fully correct the instruction gap originating within LIS programs themselves. If LIS graduates feel unprepared for instruction in traditional settings, how can they secure employment and perform well in atypical settings?

\section{PREPARATION FOR THE NEW WORK SETTING}

While many students following the advice outlined above are offered excellent positions in traditional information service settings, other students find themselves venturing outside of these positions. These graduates in particular may find themselves struggling to adapt to their new career. What advice can best help those seeking alternative careers in nontraditional settings where they will contribute through instruction?

As new graduates explore work in nontraditional settings, their job titles may also be somewhat nontraditional, in other words, "cool." Librarians working in records may be called a "Project Archivist" or "Processing Archivist," while other cool titles reflect specific types of collections or items involved, such as "Digital Media Manager," "Digital Repository Coordinator," or "Digital Asset Management Analyst." Other graduates may become "Information Architects" or "Information Security Coordinators," while some titlessuch as "Solution Designer" or "Knowledge Strategist"—are more vague, but potentially more exciting.

Searching for "instruction" (limited by "paid" and "fulltime") in our in-house database of job vacancies returned 27 current openings. We then selected the handful of job titles that were less common "Data Services Resident Librarian," "Coordinator of Digital Projects," "Information Designer," "GIS Librarian," and "Research Data Specialist") and reviewed their job descriptions for listed skills or preparation. The required or desired skills sought in these positions fell into four categories: (1) specific technical skills; (2) skills in working successfully with groups; (3) communication skills; and (4) personal attributes. These categories have the potential to significantly impact the design of library instruction curriculum within LIS programs. We briefly address technical skills and group work, and spend the remainder of 
this column focusing on how graduate education can more directly contribute to the development of communication skills and personal attributes.

LIS students are understandably concerned with acquiring the necessary technical skills and practice in specific applications to secure a future position. The technical skills mentioned in our sample of "cool job" listings included data manipulation, media coding, knowledge of digital asset management systems, knowledge of web standards, and geospatial processing software. Like students of the past who listed on their resumes the typewriters they had used or the databases they could search, today's students will mention XHTML/HTML5, CSS, JavaScript, SQL, PHP, and other technological assets. While our iSchool curriculum might not offer specific courses covering all of the technical areas listed in our sample, coupling coursework with field experience might provide a sufficient technical background for a new graduate applying for such positions.

In contrast to teaching technical skills in the iSchool curriculum, working in groups is a mainstay of our courses. By graduation, our students will have had extensive experience completing group projects. For other LIS programs looking to integrate more group work experience into their curricula, Roy and Williams have offered suggestions for employing effective collaborative-learning techniques in graduate reference courses. ${ }^{4}$ Students often incorrectly assume, however, that this participation in group work alone means they have acquired the communication skills and personal attributes that make them attractive employees. The following section provides advice on how students might take the next steps in developing their communication skills.

\section{COMMUNICATION SKILLS: THE USER INTERFACE IS A CRITICAL SKILLSET}

In our current information age, it is rare to find a professional job description that does not specify knowledge, skills, and abilities regarding communication. Understanding how to effectively convey information is more critical than everespecially in the LIS arena, where information is the desired commodity.

But what, specifically, are good communication skills? Although in our experience, few job postings actually describe what good communication means, experienced communicators know that core communication skills include clarity and understanding, focus and purpose, listening, responding and adapting, and measuring and confirming that information has been properly conveyed.

An effective communicator must clearly articulate the message, point, or information he or she is working to share. This process requires that the communicator delve into the subject at hand and fine-tune the information for the user's needs. This approach involves asking additional questions and being open to gathering more details before responding or sharing. A communicator with only a fuzzy understanding of the information in question cannot effectively take the next step, which is to focus the message with a known purpose.

Additionally, one of the most critical traits for an effective communicator is the ability to pare information down to the most useful and essential points. A communicator does a disservice to users by not doing the hard work of curating the information. Student projects that include classroom or professional presentations offer opportunities to hone this skill. Group projects further enhance this experience by requiring collaboration and compromise to focus the key presentation points. In a professional setting, the ability to communicate only the most salient points is deeply appreciated; too much information can be as unhelpful as too little information. Guided practice is essential in learning to provide the right information in the right way.

Understanding effective communication comes directly from one, often overlooked component: listening skills. Strong communicators take the time to listen to others, truly understand the information needed, and determine how best to convey that information. It is not uncommon for users to be unsure of exactly what information they're looking for or even how to ask for it. Such active listening is another skill that can be developed and refined during student group projects.

Additionally, conflict resolution involves highly skilled listening abilities that identify key issues and their solutions. While conflict, disagreement, and differing opinions may be unpleasant, they can also lead to better outcomes when handled confidently and professionally. Conflict resolution skills are valuable in every workplace. Future employers may even include questions about an applicant's specific experiences with conflict and resolution to identify applicants who can successfully navigate such situations. LIS coursework that provides students opportunities to disagree and ultimately come to agree can help them as future information specialists.

Responding also means adjusting and adapting-effective communicators leverage the valuable information acquired through active listening by altering how and what they communicate. This can entail simplifying the message, seeking better communication channels, or trying a completely different approach. This process can be iterative and ideally becomes a feedback loop for continuous improvement. Working under the philosophy that "the user is never wrong," skilled communicators are willing to change strategy when necessary and as supported by user input. Some of the most useful user feedback identifies unclear communication; being open to improvement is a marker of future success. Savvy communicators welcome constructive criticism and are not afraid to ask for it - in fact, the savviest communicators actively seek it by measuring their efforts at every opportunity. LIS students can learn this perspective by giving and receiving constructive feedback during class assignments or group work.

The best time to consider measuring communication effectiveness is at the outset of a communication effort. The 
communicator should develop a strategy in advance for determining whether or not the information conveyed was received and understood. Methods for assessment can be formal or informal; for example, communicators can use surveys or analytics, or they can simply talk to and listen to users on a regular basis. Such assessment is enhanced by ensuring that the work has already been done to provide clear information with a known purpose. Through sufficient coursework and guidance, LIS students are uniquely qualified to understand the value of providing access and assistance with relevant, useful, and meaningful information. Lastly, the role of instruction in new environments requires the LIS graduate to produce and manage internal communications, listen to different stakeholders, and translate work across groups. When preparing interviews for "cool jobs," therefore, applicants should be ready to offer stories that provide prospective employers with insight that illustrates their ability to be effective team members. Applicants should offer evidence that they are competent in fundamental skills (information management) and interpersonal skills (conflict resolution) making them ideal candidates for a changing work environment.

\section{PERSONAL ATTRIBUTES: BEHAVIORS AND ATTITUDES ARE ESSENTIAL IN THE JOB SEARCH}

An excellent employee in a "cool job" should be flexible. Therefore, graduates must translate their education, skills, and attributes to meet the stated wants of the employment setting; they must also demonstrate that their employer needs what they have to offer. By proposing new ideas and making unexpected contributions, information professionals may actively show that a single job announcement does not describe all of the needs within the employment setting, including a work setting that may never have otherwise considered hiring a librarian. In advocating for themselves, these graduates are also advocating for the LIS profession as a whole.

Seeking and retaining a "cool job" may require more risk taking on the part of the information professional who may be more familiar with the process and practice of working in traditional settings. This starts with being open to new opportunities in the job search that may require changing a career direction. This need for flexibility in the job search calls on the applicant to undergo a deep assessment of their values, skills, and comfort levels as well as conduct research on the employment market. This personal assessment should answer the fundamental question What can I do? During our face-to-face instruction delivery in the UT-Austin iSchool, we observe-to some degreethe personal attributes of our students within a formal classroom setting. As the instructors of record, we note if students submit work on time, credit other classmates in group projects, respond politely in their engagement with clients, follow instructions, or offer suggestions for improvement. However, even when students submit peerand self-evaluations of group work, we cannot always witness the energy, struggles, and strategies that arise in the collaboration. In either case, it is vital that students learn to effectively assess and develop their own personal attributes before graduating and entering the job market.

The job search requires a broader consideration of employment than one of browsing sites or sources that list traditional openings in traditional settings. Networking and connecting with prospective employers at social settings is highly important for LIS graduates, as is volunteering at settings where students can gain or test new skills. Students can further expand their reference-related search skills by imagining their ideal job and then comparing what is needed in such a scenario with a personal assessment. Confidence is a key contributing factor; students and recent graduates should affirm that anyone who can provide clarity within the world of information is an asset.

\section{PREPARING FOR THE "COOL JOB": LESSONS FOR EDUCATORS AND STUDENTS IN PREPARING FOR THE ATYPICAL CAREER}

Learning to teach information provision is an essential skill in a world where users are inundated with information. Instruction is essential in helping people clarify what they are looking for and find what they need. Making tasks clear and actionable are critical contributions in many work settings.

In summary, there is no single suggestion for preparing to be an instructional librarian in a changing work environment. The four aspects essential to this work (technical skills; collaboration; communication skills; and positive personal attributes) can and should be considered by LIS students and faculty. Our recommendations are therefore as follows:

\section{For Educators}

- Learn alongside your students.

- Follow the careers of your graduates. You may learn from their advancement, successes, and challenges. They become your educators as they enter the workforce.

- Find places for your alumni to participate in courses.

- Incorporate opportunities for students to work together and evaluate their work not only by task accomplishment but also in their ability for responsible participation including conflict resolution.

- Incorporate coursework that assists students in becoming better communicators.

- Reward risk-taking.

- Seek ways to provide service learning opportunities within your courses.

- Become aware of atypical employment opportunities for your graduates.

- Save and incorporate the success stories of your alumni. 


\section{For Students and Recent Graduates}

- Be open and responsive to change.

- Recognize opportunities.

- Shape your employment to both fit you and your employer.

- Avoid rigid thinking that may limit your job prospects.

- Continually refine your skill set.

- Return to your graduate program and help prepare the next generation of information professionals.

\section{References}

1. Saunders, Laura. "Education for Instruction: A Review of LIS Instruction Syllabi," Reference Librarian 56 (2015): 1-21.
2. "The First-Year Experience and Academic Libraries: A Select, Annotated Bibliography," Association of College and Research Libraries, 2015, accessed June 9, 2015, www.ala.org/acrl/ aboutacrl/directoryofleadership/sections/is/iswebsite/projpubs/ tmcfyebib; "Librarians Active Learning Institute at Dartmouth July 30-31, 2015," Dartmouth College Library, 2015, accessed on April 22, 2015, www.dartmouth.edu/ library/home/about/ lali/index.html.

3. Elizabeth Blakesley Lindsay and Sara Baron, "Leading Information Literacy Programs: Immersion and Beyond," Journal of Library Administration 36 (1/2) (2002): 143-65.

4. Loriene Roy and Sarah E. Williams, "Reference Education: A Test Bed for Collaborative Learning," Reference Librarian 55 (2014): 368-74. 